\title{
No evidence for leaf-trait dissimilarity effects on litter decomposition, fungal decomposers, and nutrient dynamics
}

\author{
André Frainer, ${ }^{1,2,3,4,5,11}$ Marcelo S. Moretti, ${ }^{1,6,7}$ Wenjing Xu, ${ }^{1,2,8}$ and Mark O. Gessner ${ }^{1,2,9,10}$ \\ ${ }^{1}$ Department of Aquatic Ecology, Eawag: Swiss Federal Institute of Aquatic Science and Technology, 8600 Dübendorf, Switzerland \\ ${ }^{2}$ Institute of Integrative Biology (IBZ), ETH Zurich, 8092 Zurich, Switzerland \\ ${ }^{3}$ Department of Ecology, Federal University of Rio Grande do Sul, 901501970 Porto Alegre, Brazil \\ ${ }^{4}$ Department of Ecology and Environmental Science, Umeå University, 90740 Umeå, Sweden \\ ${ }^{5}$ Department of Arctic and Marine Biology, University of Tromso, 9037 Tromsø, Norway \\ ${ }^{6}$ Department of Biology, Universidade Federal de Minas Gerais, 30161970 Belo Horizonte, Brazil \\ ${ }^{7}$ Laboratory of Aquatic Insect Ecology, University of Vila Velha, 29102920 Vila Velha, Brazil \\ ${ }^{8}$ Institute of Agricultural Engineering, Anhui Academy of Agricultural Sciences, 230031 Hefei, P. R. China \\ ${ }^{9}$ Department of Experimental Limnology, Leibniz Institute of Freshwater Ecology and Inland Fisheries (IGB), Alte Fischerhütte 2, \\ 16775 Stechlin, Germany \\ ${ }^{10}$ Department of Ecology, Berlin Institute of Technology (TU Berlin), Ernst-Reuter-Platz 1, 10587 Berlin, Germany
}

\begin{abstract}
Biodiversity and ecosystem-functioning theory suggest that litter mixtures composed of dissimilar leaf species can enhance decomposition due to species trait complementarity. Here we created a continuous gradient of litter chemistry trait variability within species mixtures to assess effects of litter dissimilarity on three related processes in a natural stream: litter decomposition, fungal biomass accrual in the litter, and nitrogen and phosphorus immobilization. Litter from a pool of eight leaf species was analyzed for chemistry traits affecting decomposition (lignin, nitrogen, and phosphorus) and assembled in all of the 28 possible two-species combinations. Litter dissimilarity was characterized in terms of a range of trait-diversity measures, using Euclidean and Gower distances and dendrogram-based indices. We found large differences in decomposition rates among leaf species, but no significant relationships between decomposition rate of individual leaf species and litter trait dissimilarity, irrespective of whether decomposition was mediated by microbes alone or by both microbes and litter-consuming invertebrates. Likewise, no effects of trait dissimilarity emerged on either fungal biomass accrual or changes during decomposition of nitrogen or phosphorus concentrations in individual leaf species. In line with recent meta-analyses, these results provide support for the contention that litter diversity effects on decomposition, at least in streams, are less pronounced than effects on terrestrial primary productivity.
\end{abstract}

Key words: biodiversity and ecosystem functioning; detritus breakdown; ergosterol fungal biomass; functional diversity; functional plant litter traits; nitrogen immobilization; phosphorus dynamics.

\section{INTRODUCTION}

Understanding the role of biodiversity in shaping ecosystem processes continues to be one of the most fundamental problems in ecology (Sutherland et al. 2013). While evidence is growing for consistent plant diversity effects on primary production (Cardinale et al. 2012, Reich et al. 2012), diversity effects on plant litter decomposition appear more idiosyncratic (Gessner et al. 2010, Lecerf et al. 2011, Cardinale et al. 2012). In particular, a recent meta-analysis demonstrated a significant overall diversity effect on litter decomposition in streams, but not in forests or grasslands (Cardinale et al. 2011), though the individual experiments analyzed showed positive, neutral, or negative effects (Srivastava et al. 2009, Lecerf et al. 2011). Thus,

Manuscript received 16 June 2014; accepted 3 July 2014; final version received 6 August 2014. Corresponding Editor: S. D. Frey.

${ }^{11}$ E-mail: andre.frainer@slu.se the topic of whether plant litter diversity affects decomposition rates remains much debated (Schindler and Gessner 2009, Gessner 2010, Lecerf and Kominoski 2010), with few of the mechanisms (e.g., microbial nutrient transfer between litter types, selective feeding on attractive litter types by detritivores [Hättenschwiler et al. 2005, Gessner et al. 2010]) hypothesized to explain litter diversity effects on decomposition being empirically tested (Schimel and Hättenschwiler 2007, Lummer et al. 2012). The lack of compelling evidence in support of, or disagreement with, the proposed mechanisms has been a major obstacle to developing a general theoretical framework to predict plant diversity effects on litter decomposition.

Despite these uncertainties, it is clear that differences among species in terms of traits affecting ecosystem processes (Suding and Goldstein 2008) are a prerequisite for diversity effects on ecosystem processes to arise (Mouillot et al. 2013). Therefore, inconsistent responses of decomposition rates to variation in plant litter 
diversity in litter mixtures might be a consequence of varying levels of trait similarity, or dissimilarity, among the constituent litter species (Schindler and Gessner 2009). However, experimental support for this hypothesis is inconclusive, prompting the question as to whether any existing diversity effects may be weakened by the criterion chosen to select litter species, the precise definition of trait diversity, or the experimental design and associated power of statistical analyses (Gessner 2010, Lecerf and Kominoski 2010). Thus, the general importance of trait dissimilarity in litter mixtures for generating diversity effects on decomposition remains unsettled.

Plant litter traits determining rates of decomposition are essentially defined by litter chemistry (Freschet et al. 2011). Litter lignin content, in particular, is a key component of litter chemistry that commonly assumes overriding importance in determining decomposition rates in a wide variety of terrestrial (Melillo et al. 1982, Freschet et al. 2011, Talbot and Treseder 2012) and aquatic environments (Hladyz et al. 2009, Schindler and Gessner 2009). Evidence from streams suggests that the often tight negative relationship between litter lignin content and decomposition rate also holds for lignin and fungal growth (Gessner and Chauvet 1994), which reflects the positive effects of fungal activity on leaf litter decomposition through both direct leaf degradation and enhanced nutritional quality of litter for subsequent invertebrate consumption (Webster and Benfield 1986, Graça 2001, Gulis et al. 2009). In addition, differences in the concentration of litter nutrients, such as nitrogen and phosphorus, also influence decomposition rates (Enriquez et al. 1993), even within the same litter species (Leroy et al. 2007). Litter nutrients in combination with litter lignin content may also affect decomposition, as is indicated by close relationships between decomposition rate and the ratio of litter lignin to nitrogen (Melillo et al. 1982) or litter lignin to phosphorus content (Wieder et al. 2009).

In the past, experimental investigations into effects on decomposition caused by plant litter diversity focused on litter mass loss only (Gartner and Cardon 2004, Hättenschwiler et al. 2005, Gessner et al. 2010, Cardinale et al. 2011). However, litter decomposition also involves nutrient transformations (immobilization and mineralization [Parton et al. 2007, Manzoni et al. 2008]), which can have important ecosystem consequences beyond the decomposition process (e.g., altered nutrient cycling in streams [Webster et al. 2009]). In addition, decomposing leaf litter is an important site of microbial biomass production, which can be extraordinarily high in streams (up to $280 \mathrm{~g}$ dry mass $\cdot \mathrm{m}^{-2} \cdot \mathrm{yr}^{-1}$ [Suberkropp et al. 2010]). As would be expected on theoretical grounds, concurrent analyses of multiple ecosystem processes in response to varying diversity of living plants have shown that the likelihood of detecting diversity effects increases with the number of processes examined (e.g., Hector and Bagchi 2007, Gamfeldt et al. 2008, 2013, Perkins et al. 2014), but whether this principle applies equally to plant litterassociated processes (e.g., fungal secondary production or nutrient immobilization and mineralization) is unknown.

In this study we used a novel experimental design to assess plant litter diversity effects on decomposition. The design has proven powerful for the detection of diversity effects of litter-consuming soil fauna on decomposition (Heemsbergen et al. 2004). This approach involves mixing leaf species differing in litter chemistry to create chemical trait dissimilarity gradients. We used this approach to investigate not only effects on litter mass loss, but also on two related processes, nutrient immobilization and fungal biomass accrual in decomposing plant litter. We hypothesized consistent relationships between the degree of litter dissimilarity and the three response variables (Fig. 1). For example, if detritivores feeding preferentially on high-quality resources use litter as both food and habitat (Richardson 1992), then decomposition rates of high-quality litter (abundant labile carbon, high nutrient contents) should increase (Fig. 1a), whereas that of the low-quality litter (recalcitrant carbon, low nutrient contents) should decrease (Fig. 1b) in leaf litter mixtures when compared to the same leaf species decomposing in isolation. Alternatively, in contrast to this invertebrate effect, microbes colonizing mixed-species leaf litter may transfer nutrients from nutrient-rich to nutrient-poor litter, thereby enhancing the decomposition of low-quality litter as dissimilarity in litter mixtures increases (Fig. 1a). Consequently, the effect of litter mixing on decomposition rates of particular leaf species need not be the same, depending on whether decomposition is mediated by microbes or whether detritivores contribute importantly as well. To test for such effects of litter diversity on decomposition, nutrient dynamics and fungal biomass accrual, we designed a decomposition experiment involving litter mixtures assembled from a pool of eight common tree species.

\section{Methods \\ Study site}

The experiment was conducted in a third-order stream, the Steina, located in the Black Forest of southwestern Germany $\left(47^{\circ} 47^{\prime} 51^{\prime \prime} \mathrm{N}, 8^{\circ} 19^{\prime} 28^{\prime \prime} \mathrm{E}\right)$. The site was located $717 \mathrm{~m}$ above sea level, about $10 \mathrm{~km}$ from its spring. The stream bed was composed of cobbles and pebbles derived from crystalline bedrock (Hieber and Gessner 2002). The stream water was circumneutral, well-oxygenated, and had moderate nutrient concentrations (Table 1). Spruce (Picea abies L.) was the dominant tree species in the forested watershed, but the riparian vegetation was composed of diverse deciduous tree species, including those used in the experiment.

\section{Litter decomposition}

We collected leaf litter of eight common European broad-leaved tree species, which were selected to 


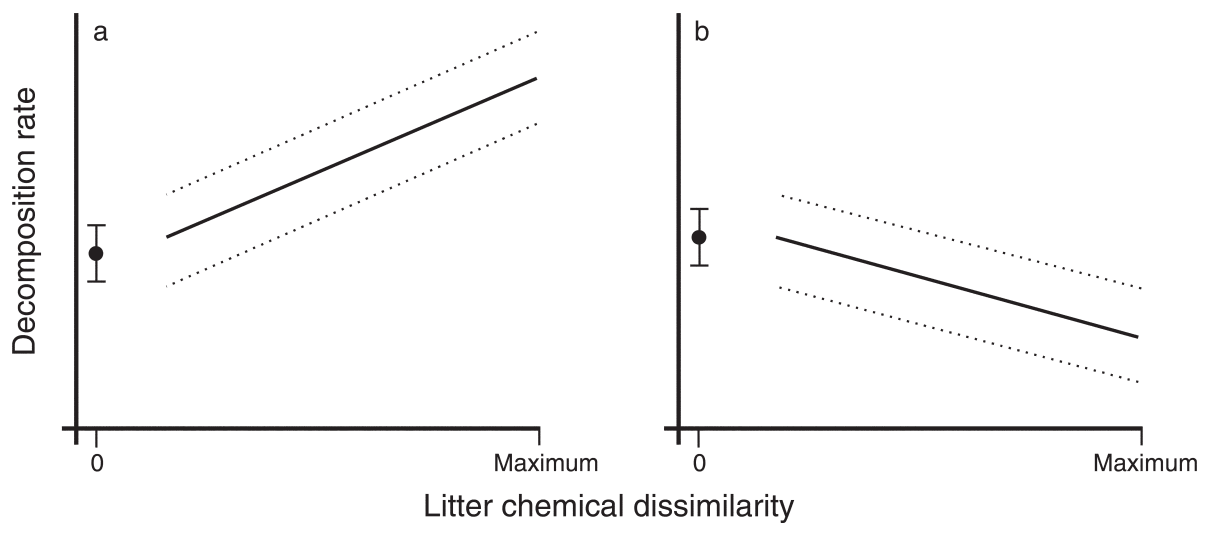

FIG. 1. Expected outcomes under the hypothesis that contrasts in litter chemical diversity generate diversity effects on decomposition rate. (a) In the presence of detritivores, increasing dissimilarity is hypothesized to accelerate decomposition of easily degradable litter species with low lignin and high nutrient contents, whereas (b) decomposition of recalcitrant species with high lignin and low nutrient contents is hypothesized to be slowed. Conversely, if microbial transfer of nutrients from nutrient-rich to nutrient-poor leaf litter is a dominant process stimulating decomposition, then recalcitrant litter would be positively affected as dissimilarity increases in litter mixtures (a). Solid lines represent mean responses and dotted lines are hypothetical confidence limits. Solid circles with vertical errors bars $( \pm \mathrm{SE}$ ) denote species decomposing in the absence of other species (i.e., no mixtures). "Maximum" is maximum chemical dissimilarity between litter species decomposing together, and 0 is no dissimilarity (i.e., species decomposing in the absence of other species).

represent a gradient of litter quality and expected to decompose at rates ranging from slow to fast. The included species were European beech (Fagus sylvatica L.), pedunculate oak (Quercus robur L.), English walnut (Juglans regia L.), silver birch (Betula pendula Roth), black poplar (Populus nigra L.), black alder (Alnus glutinosa (Gaertn.) L.), Scots elm (Ulmus glabra Huds.), and common dogwood (Cornus sanguinea L.). Leaves were picked from the ground just after abscission and air-dried for two weeks at room temperature.

We placed a total of $4.00 \pm 0.05 \mathrm{~g}$ of air-dried leaves in coarse- and fine-mesh litterbags (10 and $0.5 \mathrm{~mm}$ aperture, respectively) after spraying the leaves with chlorine-free water to make them pliant and thus avoid fragmentation during handling. Leaf litter enclosed in fine-mesh bags is accessible essentially to microbes only, whereas coarse-mesh bags also allow access of detritivorous invertebrates. Litterbags contained either a single species (8 treatments), or mixtures of two leaf species in all possible pairwise combinations (28 treatments). This resulted in a total of 72 treatments for both mesh sizes. Mixed-species litterbags received equal amounts of both leaf species $(2.00 \pm 0.05 \mathrm{~g})$. The litterbags were kept moist and cool overnight and were subsequently submerged in the stream on 19 November 2007. The bags were arranged in the stream in three blocks, each corresponding to a separate riffle. One replicate coarse-mesh bag was retrieved from each riffle after 21, 42, and 84 days, and one fine-mesh bag from each riffle after 42 days. The retrieved litter was returned to the laboratory in a cool box, sorted to species, and carefully cleaned under water. Ten leaf discs $(7 \mathrm{~mm}$ diameter) were cut for fungal biomass analyses. The remaining bulk samples were frozen at $-20^{\circ} \mathrm{C}$, freezedried, and weighed.

\section{Litter chemistry and fungal biomass}

Litter quality was initially determined in undecomposed litter (ground to pass a $0.5-\mathrm{mm}$ mesh screen) and again after 42 days of decomposition in the field. Proximate lignin was determined by the acid-detergent fiber method following Gessner (2005a). N and P concentrations were determined spectrophotometrically after digestion of ground leaf material according to Ebina et al. (1983). All lignin and nutrient concentrations were corrected for residual moisture. The quotient between initial and final litter $\mathrm{N}$ and $\mathrm{P}$ concentrations (i.e., before and after 42 days of field exposure) was calculated as an indicator of the extent to which nutrient immobilization or mineralization occurred.

Fungal biomass was estimated by measuring ergosterol content in undecomposed litter and litter retrieved after 42 days of decomposition in the stream (Gessner 2005b), a time chosen to reduce potential bias resulting from differences in fungal colonization rate of slow- and fast-decomposing leaf species. Leaf discs were cut with a cork-borer, frozen, freeze-dried, weighed, and immedi-

TABLE 1. Water chemical and temperature data recorded at the study site during the experimental period between 19 November 2007 and 8 February 2008 ( $n=$ four sampling dates).

\begin{tabular}{lcc}
\hline \hline \multicolumn{1}{c}{ Parameter } & Mean & Range \\
\hline Nitrate $(\mu \mathrm{g} \mathrm{N} / \mathrm{L})$ & 681 & $601-761$ \\
Ammonium $(\mu \mathrm{g} \mathrm{N} / \mathrm{L})$ & 7.8 & $4.4-13.1$ \\
Ortho-phosphate $(\mu \mathrm{g} \mathrm{P} / \mathrm{L})$ & 15.8 & $13.8-17.5$ \\
Alkalinity $(\mathrm{mmol} / \mathrm{L})$ & 0.40 & $0.33-0.51$ \\
Conductivity $(\mu \mathrm{S} / \mathrm{cm})$ & 80.3 & $78.2-88.5$ \\
Dissolved oxygen $(\mathrm{mg} / \mathrm{L})$ & 12.5 & $10.5-14.5$ \\
pH & 7.13 & $6.97-7.35$ \\
Temperature $\left({ }^{\circ} \mathrm{C}\right)$ & 1.5 & $0.0-5.5$ \\
\hline
\end{tabular}


ately analyzed. The analysis involved lipid extraction and saponification in $\mathrm{KOH} /$ methanol $(8 \mathrm{~g} / \mathrm{L} \mathrm{KOH})$ for 30 minutes at $80^{\circ} \mathrm{C}$ and subsequent purification by solidphase extraction (tC18 Sep-Pak Vac RC cartridges; Waters Corporation, Milford, Massachusetts, USA) (Gessner and Schmitt 1996). Final purification and quantification of ergosterol was achieved by highperformance liquid chromatography (HPLC) with a LiChrospher RP18 column (Merck KGaA, Darmstadt, Germany), methanol as the mobile phase $(1.5 \mathrm{~mL} /$ minute flow rate, $33^{\circ} \mathrm{C}$ ), and UV detection at $282 \mathrm{~nm}$. Ergosterol concentrations can be converted to fungal biomass by applying a conversion factor of $182 \mu \mathrm{g}$ ergosterol/g of dry fungal biomass (Gessner and Chauvet 1993).

\section{Data analysis}

Exponential decomposition rates $(k)$ of leaf litter were calculated for each species separately across all single- and mixed-species litterbags. Data for individual species and sampling dates at which litterbags contained on average $<20 \%$ of the initial litter dry mass were removed from analysis because the litterbag technique does not always lead to reliable data in this case (M. O. Gessner, personal observation). Decomposition rates for leaf litter from coarse-mesh bags were obtained by nonlinear regression procedures with fixed intercepts, based on the assumption that $100 \%$ litter mass was present at the beginning of the experiment. Decomposition rates of litter in fine-mesh bags were computed based on leaf mass remaining after 42 days, assuming first-order decay kinetics. Decomposition rates of single species were related to a range of initial litter chemistry variables by linear or nonlinear regression analyses (linear relationship for $\mathrm{N}$ and $\mathrm{P}$; power function relationships for lignin, lignin: $N$, lignin: $\mathrm{P}$, and $\mathrm{N}: \mathrm{P}$ ) using the $\mathrm{R}$ statistical software (R Development Core Team 2012).

We calculated four trait dissimilarity indices of litter mixtures based on initial litter chemistry. The variables included were the initial concentrations of lignin, $\mathrm{N}$, and $\mathrm{P}$ in all possible combinations, including the three single variables alone $(n=7)$. Lignin and nutrient concentrations were subjected to $Z$-score standardization performed with the base package in $\mathrm{R}$ ( $\mathrm{R}$ Development Core Team 2012) before dissimilarity calculations and statistical analyses. Pearson's product moment correlations were used to test for relationships among the three leaf chemistry variables. Trait dissimilarities based on one- and two-variable combinations were calculated as the pairwise distances between litter species (Walker et al. 1999) using Euclidean distances (R package cluster; Maechler et al. 2011). The three-variable combination was analyzed using four dissimilarity indices. Specifically, we calculated the pairwise distances between litter species using Euclidean or Gower distances (R package ecodist; Goslee and Urban 2007) and also assessed the branch length of functional dendrograms (Petchey and Gaston 2002) using both Euclidean and Gower distances and UPGMA as the clustering method ( $\mathrm{R}$ package vegan; Oksanen et al. 2011). Relationships between the different dissimilarity measures were assessed with Pearson's product moment correlation coefficient ( $\mathrm{R}$ package stats; R Development Core Team 2012).

We performed mixed-effect models (MEM) to test whether each of the four response variables (decomposition rate, ergosterol concentration, and differences in $\mathrm{N}$ and $\mathrm{P}$ concentration) were independently related to each of the above dissimilarity indices. We also tested for differences among litter species and their interaction with the dissimilarity index, running all possible models containing each of the dissimilarity indices. However, we were specifically interested in ascertaining whether (1) decomposition rates and fungal biomass were affected by the trait dissimilarity integrating all three variables (i.e., N, P, and lignin), or lignin alone; (2) fungal biomass was affected by dissimilarities relating to litter $\mathrm{N}$ and $\mathrm{P}$; (3) $\mathrm{N}$ dynamics were affected by litter dissimilarities defined by $\mathrm{N}$ only; and (4) $\mathrm{P}$ dynamics were affected by dissimilarities due only to P. Spatial blocks (stream riffles) were entered as a random effect in all models to control for potential spatial variation among riffles. Analyses were conducted with the $\mathrm{R}$ package nlme (Pinheiro et al. 2012). Ergosterol data (log-transformed) and differences in $\mathrm{N}$ and $\mathrm{P}$ concentrations were analyzed for litter in coarse-mesh bags. Analyses of decomposition rates included data from coarse-mesh and fine-mesh bags, with mesh size included as a third fixed effect, fully crossed with the other two fixed effects. C. sanguinea was excluded from our mixedmodel analyses on differences in $\mathrm{N}$ and $\mathrm{P}$ concentrations, because litter often had insufficient mass remaining for chemical analyses after 42 days.

\section{RESUlTS \\ Leaf litter decomposition rates}

Across all possible combinations, decomposition rates of individual leaf species in coarse-mesh bags differed almost 100 -fold, from $0.0007 \mathrm{~d}^{-1}$ for $F$. sylvatica (singlespecies bags) to $0.0634 \mathrm{~d}^{-1}$ for $C$. sanguinea (singlespecies bags) (Appendix A: Table A1). Decomposition rates of individual leaf species in fine-mesh bags differed more than 10-fold, ranging from $0.0024 \mathrm{~d}^{-1}$ for $F$. sylvatica (when mixed with $C$. sanguinea) to $0.0390 \mathrm{~d}^{-1}$ for $C$. sanguinea (single-species bags) (Appendix A: Table A2). After 42 days of decomposition, $F$. sylvatica had $\sim 85 \%$ of the initial dry mass remaining, whereas $C$. sanguinea had $<10 \%$ remaining, pooled across all treatments for coarse-mesh bags. For fine-mesh bags, F. sylvatica had $\sim 87 \%$ of the initial mass remaining and C. sanguinea $36 \%$.

\section{Litter chemistry and relationships with decomposition rate}

The eight litter species included in the experiment differed 3.4- to 22-fold in their proximate lignin, nitrogen, and phosphorus concentrations, but the species ranking varied according to the parameters 

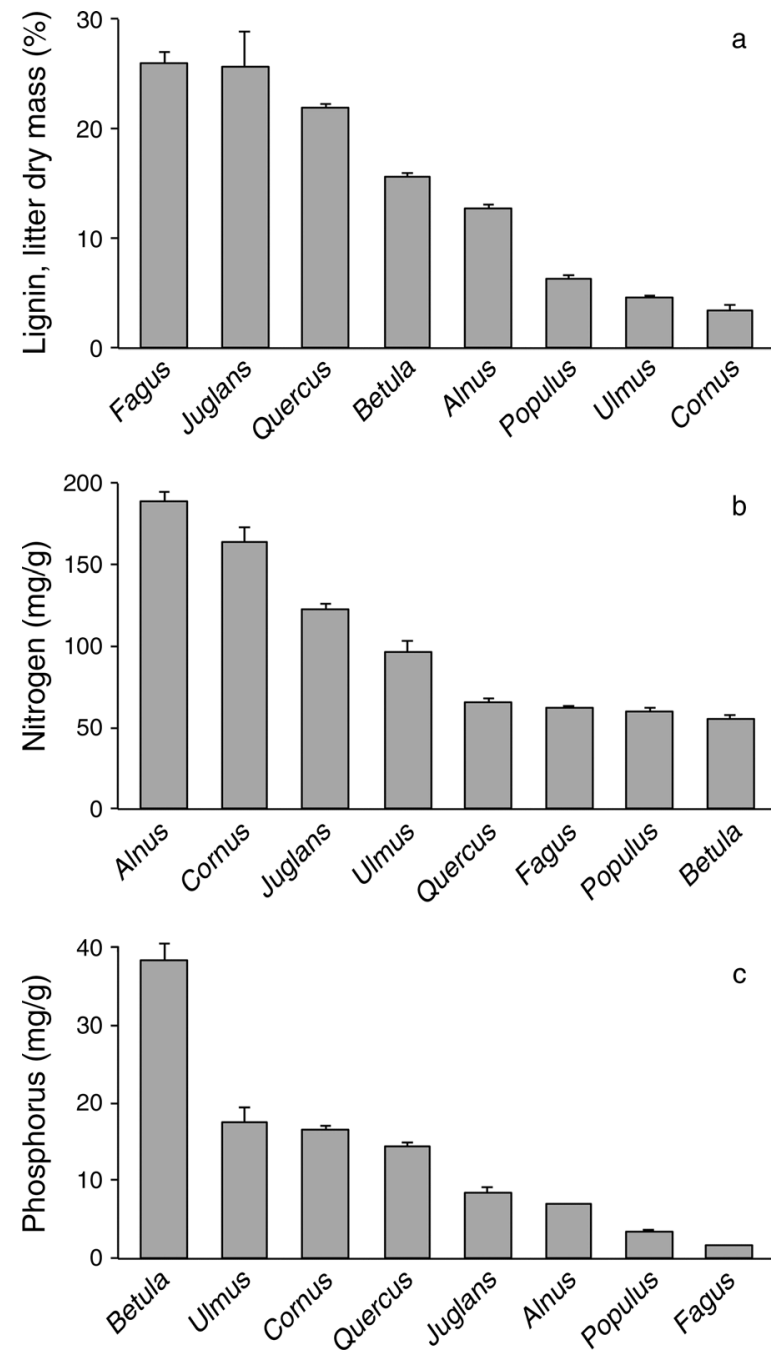

FIG. 2. Initial concentrations (mean $+\mathrm{SE}$ ) of proximate (a) lignin, (b) nitrogen, and (c) phosphorus of eight leaf litter species. Species are ranked from the highest to lowest concentration in each panel.

analyzed (Fig. 2). Proximate lignin concentrations ranged from $3.5 \%$ of litter dry mass for $C$. sanguinea to $26.1 \%$ for $F$. sylvatica (Fig. 2a). The initial $\mathrm{N}$ concentration was lowest for B. pendula $(5.6 \mathrm{mg} / \mathrm{g}$ litter dry mass) and highest for A. glutinosa $(18.9 \mathrm{mg} / \mathrm{g}$ ) (Fig. 2b), while the initial $\mathrm{P}$ concentration was lowest for $F$. sylvatica $(0.17 \mathrm{mg} / \mathrm{g})$ and highest for $B$. pendula $(3.82$ $\mathrm{mg} / \mathrm{g}$ ) (Fig. 2c). The molar ratio of nitrogen to phosphorus (N:P) was lowest for B. pendula (3.2) and highest for F. sylvatica (78.3). Concentrations of N, P, and lignin were not significantly correlated across the eight litter species $(r=0.18-0.29, P=0.48-0.67)$.

Lignin had high explanatory power in models predicting decomposition rates of single-species litter in both coarse-mesh $\left(r^{2}=0.65, P=0.009\right)$ and fine-mesh $\left(r^{2}=0.89, P<0.001\right)$ bags (Fig. 3). Decomposition rate in coarse-mesh and fine-mesh bags was also related to the initial lignin : $\mathrm{N}$ ratio $\left(r^{2}=0.66, P=0.009\right.$ for both mesh sizes), and to the initial lignin: $\mathrm{P}$ ratio $\left(r^{2}=0.55, P\right.$ $=0.02$ for both mesh sizes), but not to the initial $\mathrm{N}: \mathrm{P}$ ratio or the initial $\mathrm{N}$ or $\mathrm{P}$ concentration $(P>0.1)$.

Most dissimilarity indices based on two or three variables describing litter quality were highly correlated with each other. Specifically, the correlation coefficients between the three-variable dissimilarities calculated as Gower and Euclidean distances were $0.94(t=19.7, \mathrm{df}=$ $54, P<0.01)$ and those between dendrograms based on Euclidean and Gower distances were $0.95(t=23.4, \mathrm{df}=$ $54, P<0.01)$. Correlations between the dendrogrambased indices and the two other dissimilarity measures were $\sim 0.75(P<0.01)$.

Overall, decomposition rates of single leaf species in coarse- or fine-mesh bags were not tightly related to the dissimilarity indices tested (Table 2; Appendix B: Table B1). In particular, the relationship between decomposition rate and the Euclidean distance dissimilarity index based on three variables (lignin, $\mathrm{N}$, and $\mathrm{P}$ ) was far from significant $\left(F_{1,344}=0.02, P=0.88 ;\right.$ Fig. 4$)$, and significant
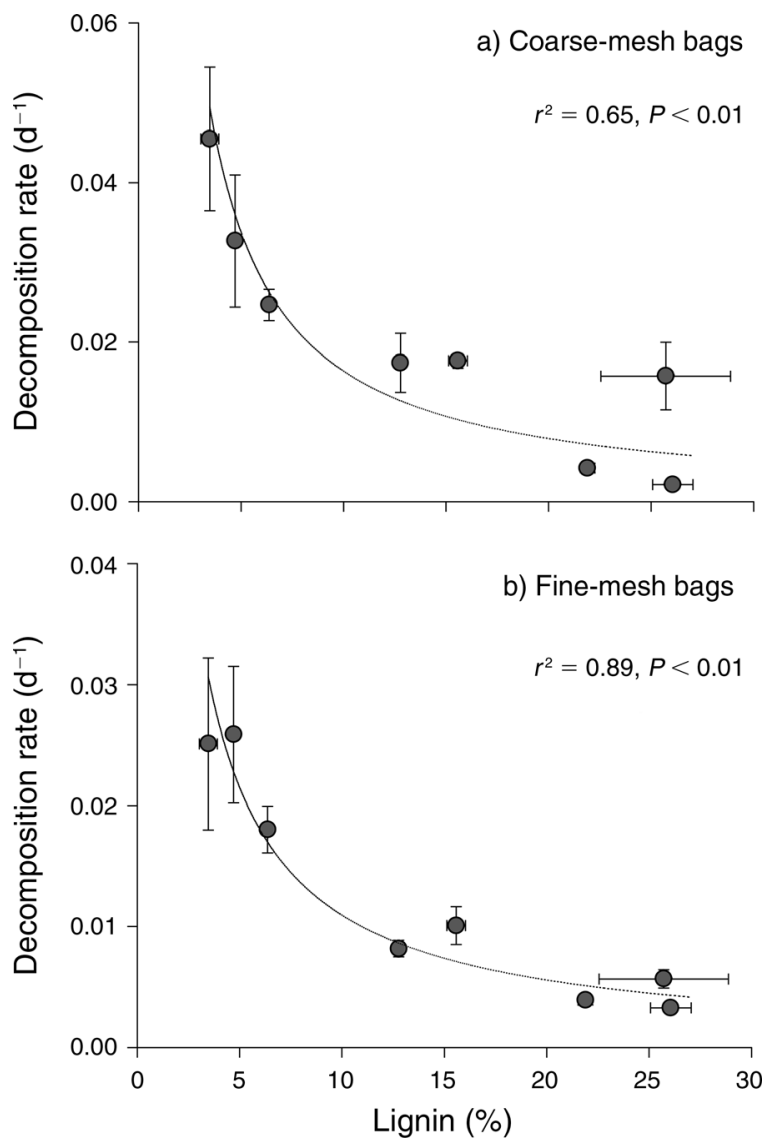

FIG. 3. Power-function relationship (trend lines) between proximate lignin concentrations and decomposition rate coefficients ( $k$ values) for (a) coarse-mesh and (b) fine-mesh litterbags containing single species. Horizontal and vertical error bars show \pm SE. $R^{2}$ values are adjusted coefficients of determination. 
interactions were also lacking between dissimilarity and litter species $\left(F_{7,344}=0.39, P=0.91\right)$, dissimilarity and mesh size $\left(F_{1,344}=0.01, P=0.91\right)$, and the three-way interaction between dissimilarity, litter species, and mesh size $\left(F_{7,344}=0.39, P=0.95\right)$ (Table 2$)$. The relationship between decomposition rate and Euclidean distance based on lignin alone was marginally significant $(P=$ 0.044 ) when the full model was assessed. However, the $P$ value increased to 0.29 when the nonsignificant three-way interaction was removed from the model, which slightly improved the model fit $(\mathrm{AIC}=-2533)$ compared to the model with the interaction included $(\mathrm{AIC}=-2525)$.

\section{Fungal biomass}

Fungal biomass estimated as ergosterol concentration of freshly collected litter was minimal, ranging from undetectable ( $P$. nigra) to $6.3 \mu \mathrm{g}$ ergosterol/g litter dry mass (J. regia). After 42 days of exposure in the field, concentrations had greatly increased, from $120 \mu \mathrm{g} / \mathrm{g}$ in Q. rubra to $883 \mu \mathrm{g} / \mathrm{g}$ in B. pendula. There were large differences among species $(P<0.01)$, but none of the tested dissimilarity indices was significantly related to changes in ergosterol concentration (all $P$ values $>0.05$; Fig. 5a and Table 2 for Euclidean distances; Appendix B: Table B2 for other dissimilarity indices).

\section{Changes in nutrient concentration}

There were large differences in $\mathrm{N}$ and $\mathrm{P}$ concentration changes among litter species during 42 days of decomposition in the stream $(P<0.01)$. Nitrogen concentrations increased for most species, with $B$. pendula and $P$. nigra experiencing the highest gains (Appendix C: Table $\mathrm{C} 1$ ). Changes in $\mathrm{P}$ concentrations ranged from declines (B. pendula, C. sanguinea, Q. robur, $U$. glabra) to gains (all other species and especially $P$. nigra and F. sylvatica) (Appendix C: Table C1). There was no effect of any of the dissimilarity indices on changes in $\mathrm{N}$ or $\mathrm{P}$ concentration $(P>0.05$; Table 2 , Fig. 5b, c; Appendix B: Tables B3 and B4). In particular, the relationship between $\mathrm{N}$ dynamics and trait dissimilarity based solely on $\mathrm{N}$ concentration was nonsignificant $\left(F_{1,122}=0.81, P=0.37\right)$, with at best a marginal interaction effect between trait dissimilarity and litter species on $\mathrm{N}$ dynamics $\left(F_{1,122}=1.92, P=0.08\right)$. There was also no relationship between $\mathrm{P}$ dynamics and trait dissimilarity based on $\mathrm{P}$ concentration $\left(F_{1,122}=0.08, P=\right.$ $0.77)$, or the interaction between trait dissimilarity and litter species $\left(F_{1,122}=1.80, P=0.10\right)$.

\section{DisCUSSION}

\section{Effects of litter trait dissimilarity on decomposition}

Our experiment assessed litter mixture effects on decomposition along litter dissimilarity gradients generated by assembling all of the 28 pairwise species combinations that are theoretically possible given a pool of eight species. Despite the large scope of this experiment and marked differences in litter chemistry among species, ranging from fast-decomposing dog-
TABLE 2. Results of mixed-effect model (MEM) analyses testing for effects of trait dissimilarity on decomposition rates (in coarse-mesh and fine-mesh litterbags), $\mathrm{N}$ and $\mathrm{P}$ dynamics (coarse-mesh bags), and ergosterol concentration (coarse-mesh bags).

\begin{tabular}{|c|c|c|c|}
\hline $\begin{array}{l}\text { Response variable and fixed } \\
\text { effects (indented) }\end{array}$ & df & $F$ & $P$ \\
\hline \multicolumn{4}{|l|}{ Decomposition } \\
\hline Intercept & 1,344 & 432.48 & $<0.001$ \\
\hline Litter dissimilarity & 1,344 & 0.66 & 0.42 \\
\hline Litter species & 7,344 & 41.46 & $<0.001$ \\
\hline Mesh size & 1,344 & 9.80 & 0.002 \\
\hline Dissimilarity $\times$ species & 7,344 & 0.24 & 0.97 \\
\hline Dissimilarity $\times$ mesh size & 1,344 & 0.01 & 0.97 \\
\hline Species $\times$ mesh size & 7,344 & 4.40 & $<0.001$ \\
\hline Dissimilarity $\times$ species $\times$ mesh size & 7,344 & 0.35 & 0.935 \\
\hline \multicolumn{4}{|l|}{ Nitrogen } \\
\hline Intercept & 1,122 & 58.88 & $<0.001$ \\
\hline Litter dissimilarity & 1,122 & 0.25 & 0.62 \\
\hline Litter species & 6,122 & 31.17 & $<0.001$ \\
\hline Dissimilarity $\times$ species & 6,122 & 1.41 & 0.21 \\
\hline \multicolumn{4}{|l|}{ Phosphorus } \\
\hline Intercept & 1,122 & 75.16 & $<0.001$ \\
\hline Litter dissimilarity & 1,122 & 0.17 & 0.68 \\
\hline Litter species & 6,122 & 159.59 & $<0.001$ \\
\hline Dissimilarity $\times$ species & 6,122 & 0.70 & 0.65 \\
\hline \multicolumn{4}{|l|}{ Fungal biomass } \\
\hline Intercept & 1,123 & 2643.57 & $<0.001$ \\
\hline Litter dissimilarity & 1,123 & 0.01 & 0.90 \\
\hline Litter species & 7,123 & 22.49 & $<0.001$ \\
\hline Dissimilarity $\times$ species & 7,123 & 1.54 & 0.16 \\
\hline
\end{tabular}

Notes: Litter dissimilarity was based on Euclidean distance. In all MEM, spatial blocks were treated as random effects. Block effects were never significant and therefore are not presented here. Statistically significant results $(P<0.05)$ are highlighted in boldface type.

wood to recalcitrant beech, there was no indication in our experiment that decomposition was affected by mixing leaf species differing in chemical characteristics. Our no-effect result sharpens the conclusion of Schindler and Gessner (2009) who found litter-mixture effects on decomposition to be weak. Importantly, our experimental design addressed various previously raised issues (Gessner 2010, Lecerf and Kominoski 2010), including a potential lack of statistical power to detect diversity effects, by assessing responses to litter dissimilarity within two-species mixtures on a continuous scale, based on litter chemistry traits known to affect decomposition (Melillo et al. 1982, Hladyz et al. 2009, Schindler and Gessner 2009, Talbot and Treseder 2012).

Our results also add importantly to recent metaanalyses which were conducted to test for the overall effects of litter diversity on decomposition rates across a range of ecosystems, but could not test for effects on individual leaf species in litter mixtures due to a lack of data. No overall litter diversity effect was found across 52 observations compiled from 27 independent studies in both terrestrial and aquatic ecosystems, even after controlling for potentially confounding factors (Srivastava et al. 2009). Analysis of an extended data set including 84 observations did reveal an overall effect, 
a) Coarse-mesh bags

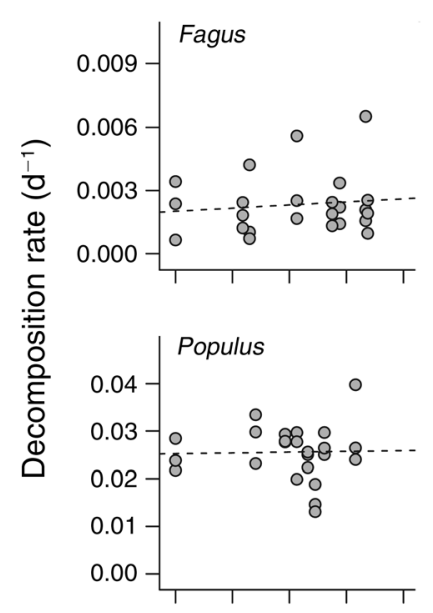

b) Fine-mesh bags

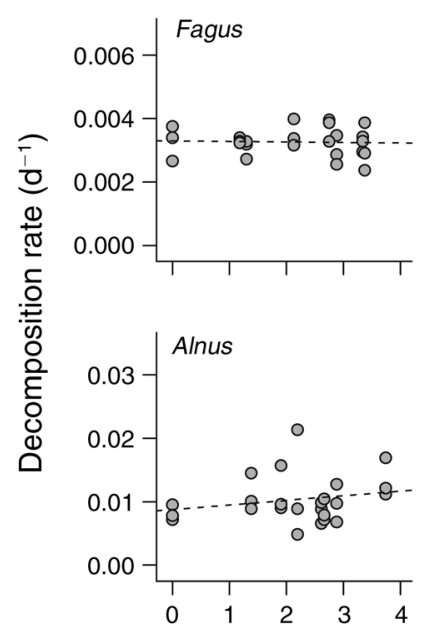

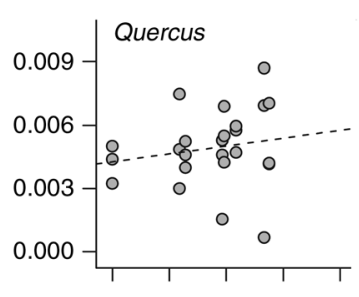
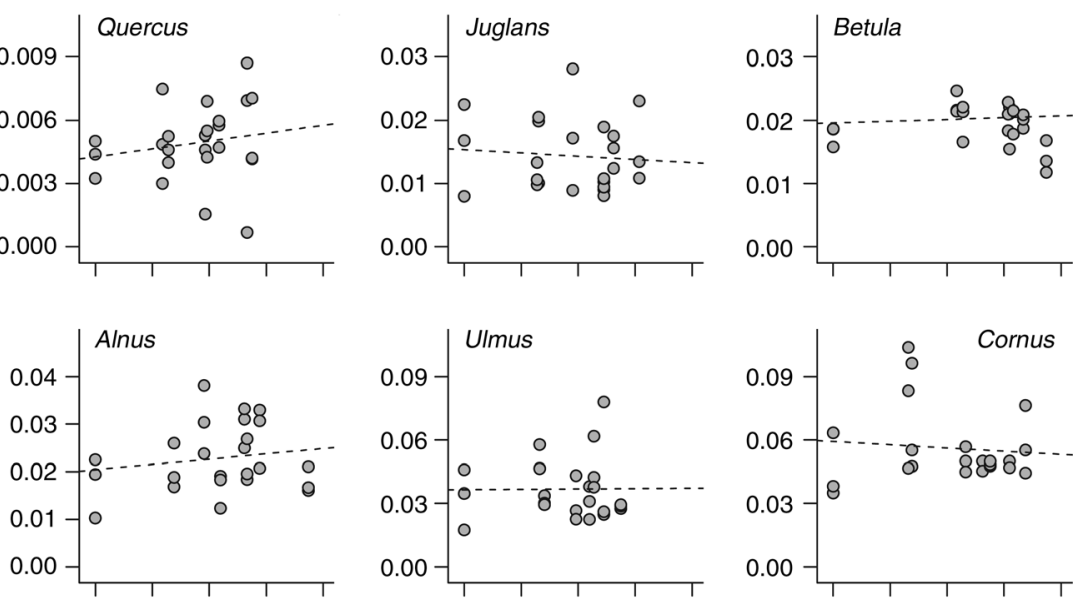
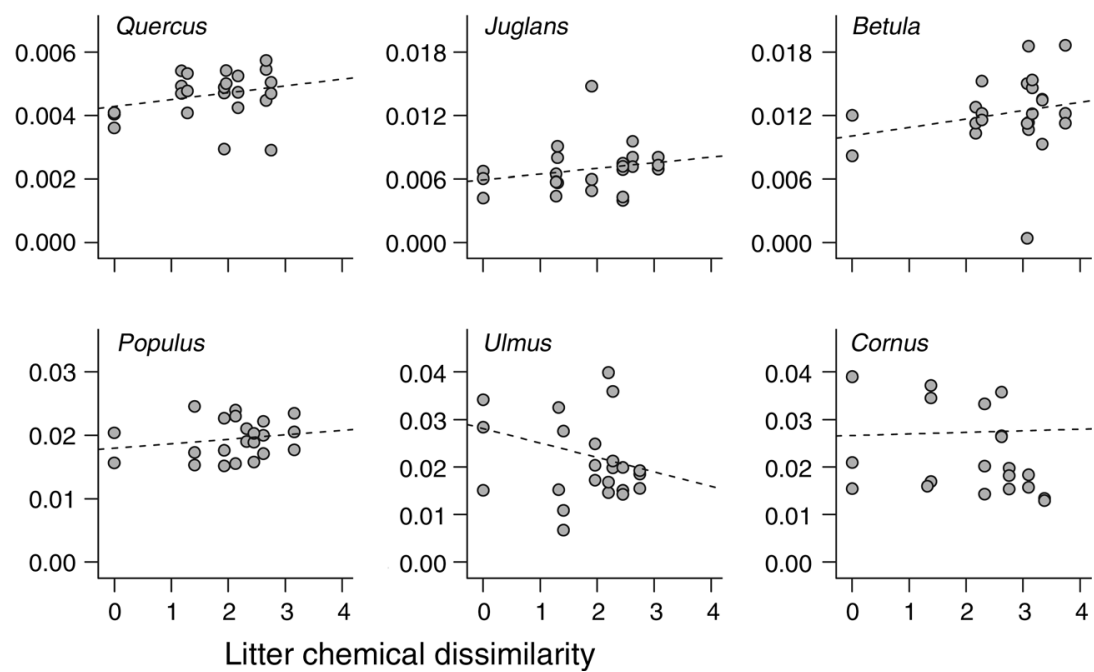

FIG. 4. Relationships between litter dissimilarity measured as Euclidean distance and decomposition rate coefficients ( $k$ values) of mixed- and single-species litter in (a) coarse-mesh and (b) fine-mesh litterbags. Dissimilarity $=0$ in single-species litterbags and $>0$ in mixed-species bags. Trend lines represent the best linear fit for each species. Litter dissimilarity was not a good predictor of variation in the response variable. Species are ranked according to decomposition rate from low to high.

but results were inconsistent across ecosystem types (Cardinale et al. 2011). Grasslands and forests showed no effects, whereas decomposition in streams was accelerated. However, litter in mixtures lost only an average of $5 \%$ more mass than litter in single-species treatments, and the overall net outcome was driven by a small number of observations, the great majority showing neither positive nor negative effects (Cardinale et al. 2011). This led the authors to conclude that overall litter diversity effects on decomposition are rather weak, especially when compared to plant diversity effects on biomass production. Finally, two other meta-analyses of 11 and 13 studies conducted in streams also suggest that litter diversity effects are weak (Lecerf et al. 2011) or lacking (Lecerf and Richardson 2009), with the decomposition rates in litter mixtures being closely correlated with the corresponding decomposition rates from singlespecies treatments $(r=0.89$ [Lecerf et al. 2011]).

The lack of litter mixture effects on decomposition in the present study occurred even though differences in decomposition rate among single-species litterbags were large (thus creating a long gradient) and highly predictable based on the initial litter lignin content. Although tight power-function relationships with decomposition rate have often shown lignin to be the single most important factor governing decomposition rates of leaf litter in streams (Hladyz et al. 2009, Schindler and Gessner 2009) and other environments (Melillo et al. 1982, Freschet et al. 2011, Talbot and Treseder 2012), dissimilarity in lignin content failed to slow or accelerate the decomposition of individual species within litter mixtures. This outcome was independent of whether 

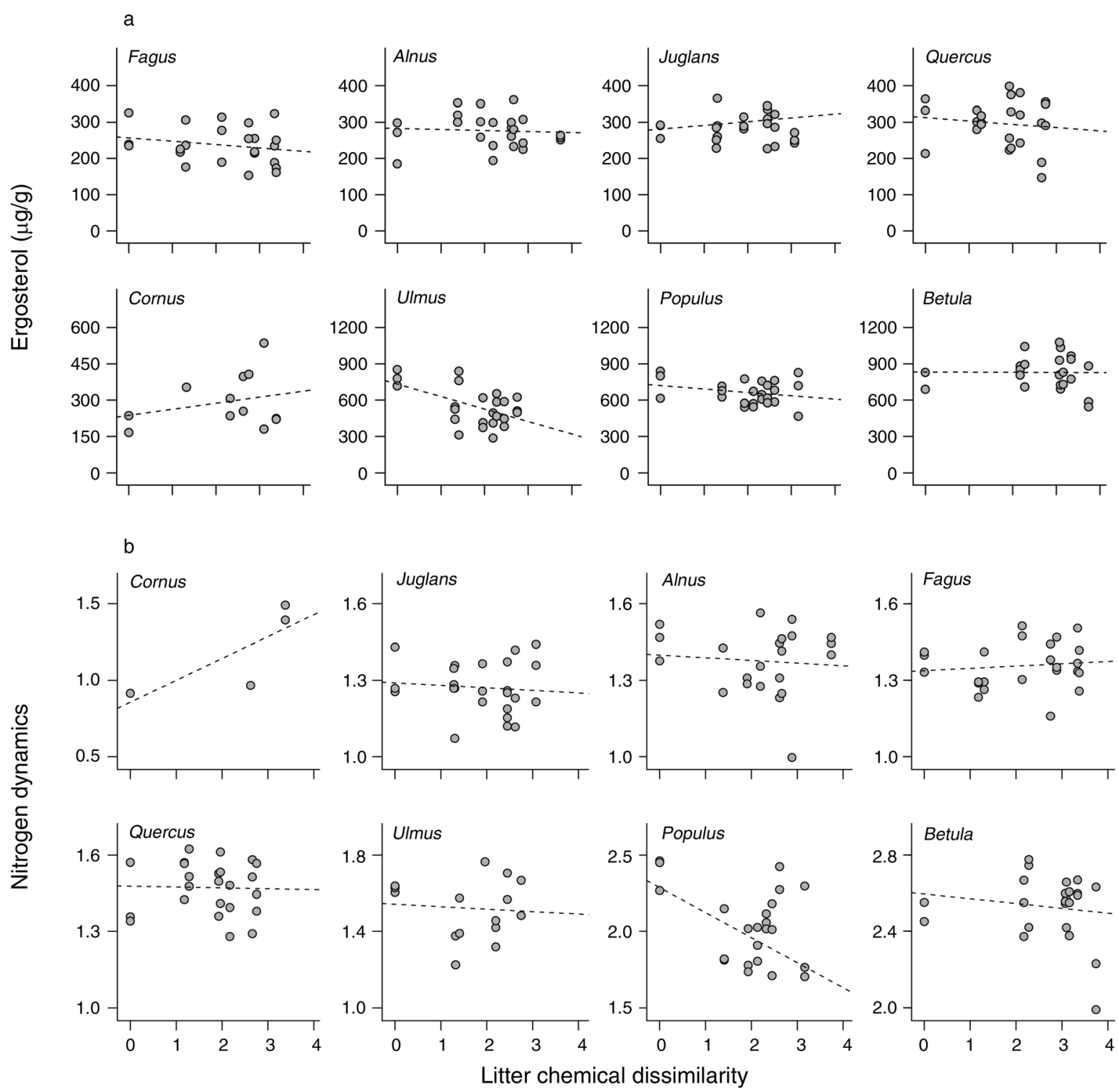

FIG. 5. Relationship between litter dissimilarity measured as Euclidean distance and each of three response variables: (a) fungal biomass as ergosterol concentration ( $\mu \mathrm{g} / \mathrm{g}$ litter dry mass), (b) changes in nitrogen concentration, and (c) changes in phosphorus concentration. Changes in nitrogen and phosphorus concentrations are expressed as the quotient of the initial and final concentrations of each element. Dissimilarity $=0$ in single-species litterbags and $>0$ in mixed-species bags. Trend lines represent the best linear fit for each species. Litter dissimilarities of litter mixtures did not explain variation in any of the three response variables $(P>0.05)$. Species are ranked from the lowest to the highest concentration.

dissimilarity was calculated based on litter lignin content alone or on lignin content in combination with litter nutrient concentrations. Indeed, the various combinations of litter chemistry variables that we used to calculate trait dissimilarity produced very similar results, revealing that the observed lack of effects was independent of the particular chemistry variables used to assess dissimilarity within the litter mixtures.

The choice of metrics to calculate dissimilarity could strongly influence the evaluation of relationships between trait dissimilarity and ecosystem processes, and has been a cause of controversy (Podani and Schmera
2006, Petchey and Gaston 2007). However, in the present study, differences in approach or computational details proved not to influence outcomes of the relationships between mixed-litter dissimilarity and decomposition rate. That is, none of a range of advocated metrics (Walker et al. 1999, Petchey and Gaston 2002, Podani and Schmera 2006, Schleuter et al. 2010) that we assessed were significantly related to litter decomposition rate, irrespective of whether decomposition was mediated by microbes alone (decomposition in fine-mesh litterbags) or by macroinvertebrates and microbes in concert (data from coarse-mesh bags). 

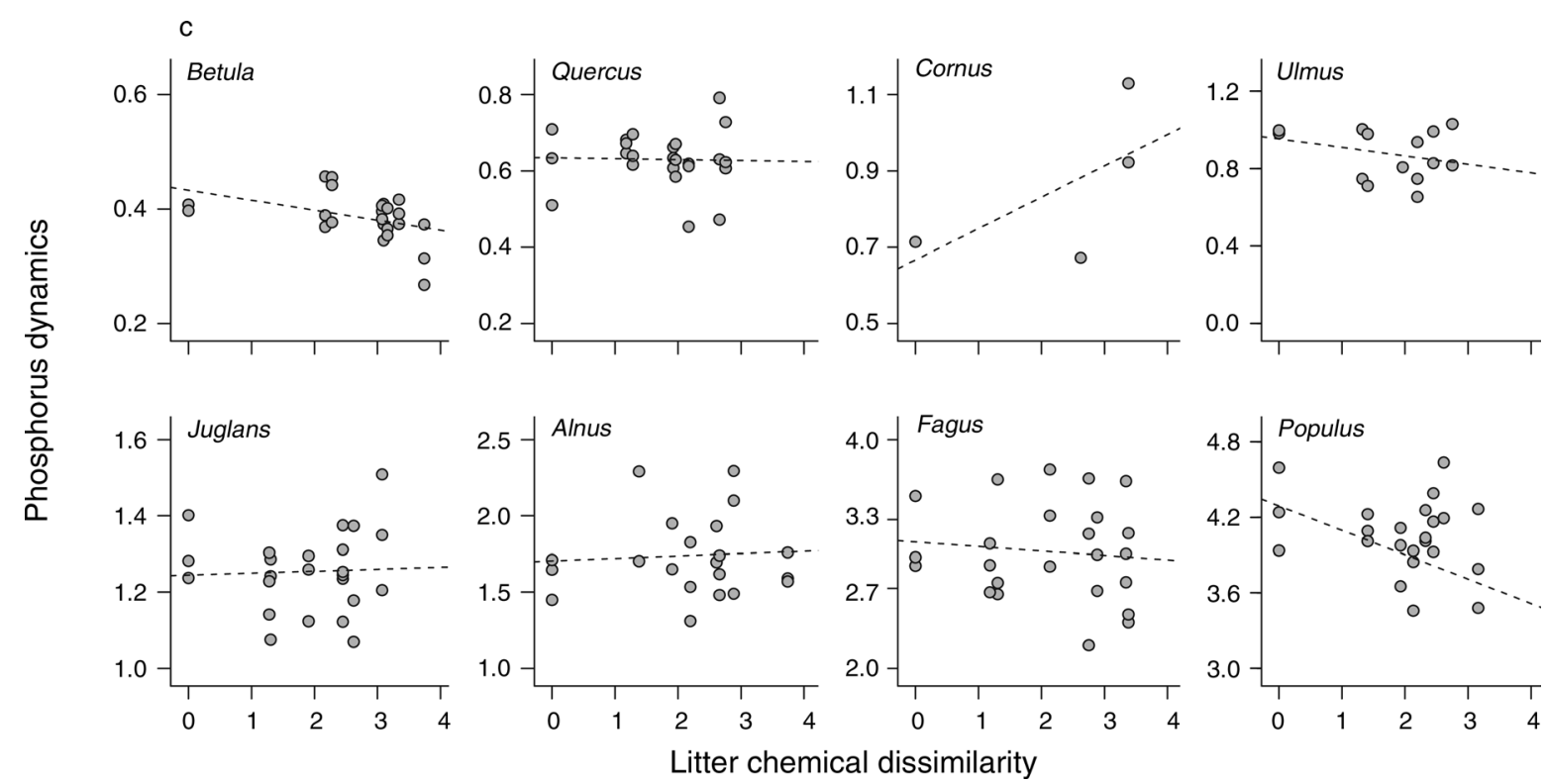

FIG. 5. Continued.

\section{Responses of fungi and nutrient dynamics to litter dissimilarity}

We hypothesized that fungal biomass in high-quality litter would be positively affected when the $\mathrm{N}$ and $\mathrm{P}$ concentrations of the constituent leaf species in litter mixtures differ widely, as captured by our dissimilarity metrics. Filamentous fungi, including the aquatic hyphomycetes that dominate fungal communities on decomposing leaves in streams (Krauss et al. 2011), can extend their hyphae over considerable distances to acquire remote resources that they transport to locations of active hyphal growth (Ritz 2006). Although theory suggests that fungi colonizing mixed-species litter could tap $\mathrm{P}$ in high-P litter while assimilating $\mathrm{N}$ from high- $\mathrm{N}$ litter to alleviate limitation by either element and maximize growth rate, we did not find support for this expectation in our experiment. Fungal biomass was largely dependent on the litter species in which it was growing, rather than on the trait dissimilarity of the litter mixture, lending support to the idea that litter composition is a more powerful predictor of microbial biomass than litter diversity (Kominoski et al. 2007).

Despite the lack of litter diversity effects on fungal growth, evidence from terrestrial microcosm experiments with isotopic tracers suggests that nutrient transfer across litter species can indeed occur (Schimel and Hättenschwiler 2007, Lummer et al. 2012), an outcome that is further supported by a recent large-scale field experiment (Handa et al. 2014). This mechanism, which could be due to nutrient translocation within hyphal networks of fungi, would also alter nutrient contents of individual litter species, depleting nutrients in source litter and enriching the receiving litter. In the present study, N, P, and lignin contents differed widely across the eight litter species included in the experiment, and these litter chemistry variables were not correlated with one another, thereby creating a situation favorable to complementary resource acquisition. Furthermore, relative $\mathrm{N}$ increases differed among litter species, and $\mathrm{P}$ rich species lost $\mathrm{P}$, while $\mathrm{P}$-poor species gained $\mathrm{P}$, indicating considerable potential for nutrient transfers during our decomposition experiment.

These conditions notwithstanding, our results indicate that litter dissimilarity affected neither fungal biomass nor $\mathrm{N}$ or $\mathrm{P}$ dynamics, regardless of whether $\mathrm{N}, \mathrm{P}$, lignin or any combination of these variables was used as the measure of litter dissimilarity. It is possible that the lack of effects reflects preferential allocation of resources to fungal reproduction (i.e., formation and release of spores), as opposed to biomass accumulation. Massive spore production is a salient life-history feature of aquatic hyphomycetes that leads to permanent loss of fungal biomass and nutrients from decomposing litter (Suberkropp 1991, Hieber and Gessner 2002). However, another simple explanation for the lack of litter dissimilarity effects is that remote fungal nutrient acquisition and translocation in heterogeneous litter mixtures was ineffective. This is the more likely scenario, since stimulation of fungal growth and reproduction are expected to be positively associated with enhanced decomposition (Gessner and Chauvet 1994), which proved to be unresponsive to litter dissimilarity as well.

\section{Environmental and biological constraints on litter diversity effects}

Elevated nutrient concentrations in stream water could account for the lack of effects in our experiments, if enough nutrients were provided to make fungal nutrient transfer from one litter species to another 
unnecessary. Dissolved nutrients are well known to affect fungal decomposers and the decomposition of leaf litter in streams (Ferreira et al. 2006, Rosemond et al. 2010). Saturating nitrate concentrations beyond which no further stimulation occurs are around $200 \mu \mathrm{g} \mathrm{N} / \mathrm{L}$ (Ferreira et al. 2006), a threshold considerably lower than the concentrations in our study stream, and likely in any other streams of Central Europe (Woodward et al. 2012) and many other parts of the world (Vörösmarty et al. 2010). Similar arguments hold for phosphorus. Conceivably, therefore, cultural nutrient enrichment of streams at large spatial scales could have obliterated any litter-mixing effects on decomposition mediated by microbial nutrient transfer. This idea is in accordance with the cancellation of an antagonistic litter-mixing effect on decomposition when a small stream with background nutrient concentrations an order of magnitude lower was experimentally fertilized (Rosemond et al. 2010).

Litter-consuming invertebrates can simultaneously exploit multiple litter species to meet their elemental demands (Leroy and Marks 2006). Accordingly, chemical dissimilarity of litter mixtures in terrestrial ecosystems has been found to stimulate decomposition due to complementary resource use by detritivores (Vos et al. 2013). In our study, invertebrates were allowed to move freely into and out of the experimental litterbags submerged in the field. This situation mimics natural conditions in streams where leaf packs accumulate behind retention structures in riffles, but it provides no information about the effective foraging range of the consumers. In contrast, by enclosing detritivores in litter-containing microcosms, Vos et al. (2013) could distinguish between feeding on single and multiple litter species. Similar experiments would have to be conducted in streams (McKie et al. 2009) to test whether consumermediated litter dissimilarity effects could arise at the stream-reach scale rather than at the litterbag scale examined in the present study.

Simultaneous assessments of multiple ecosystem processes have shown that the likelihood of detecting diversity effects increases with the number of processes considered (e.g., Hector and Bagchi 2007, Gamfeldt et al. 2008, 2013, Perkins et al. 2014). That this pattern did not emerge in the present study might be due to the fact that the three processes we examined (litter mass loss, fungal biomass accrual, and nutrient immobilization) are all tightly interlinked by the activity of fungal decomposers. Litter consumers may play a role as well, for instance by feeding selectively on litter colonized by fungi (Arsuffi and Suberkropp 1989, Graça 2001). Consequently, our results cannot strictly be interpreted in terms of multifunctionality. Generalizing our results to other ecosystems requires caution as well, especially for streams outside Central Europe (Bretherton et al. 2011), where humans have often had less influence on dissolved nutrient concentrations than in regions of the world that are densely populated, highly industrialized, or used for intensive agriculture (Vörösmarty et al. 2010). Nonetheless, the lack of systematic effects we found for a range of individual species along dissimilarity gradients of litter mixtures suggests that strong litter diversity effects on decomposition are far from being a universal phenomenon. A next step would be to identify the specific circumstances under which such effects can still arise (e.g., a combination of litter in mixtures with high vs. low ratios of labile $\mathrm{C}$ to $\mathrm{N}$ [Handa et al. 2014]) and we posit that external nutrient supply can act as a critical controlling factor.

\section{ACKNOWLEDGMENTS}

We thank M. Schindler for discussions on the experimental design and valuable help in the field and laboratory; D. Steiner, R. Illi, and the AUA lab at Eawag for support with chemical analyses; and B. G. McKie, A. Bruder, M. Duarte, A. Frossard, and several anonymous reviewers for constructive comments on the manuscript. A. Frainer thanks CAPES (Brazil) and the Swiss Federal Commission for Scholarships for Foreign Students (CFBE) for granting fellowships, and G. G. Rodrigues for continuous encouragement. M. S. Moretti and W. $\mathrm{Xu}$ also acknowledge fellowships received from CAPES and $\mathrm{CNPq}$ (Brazil) and CFBE, respectively, to facilitate their stays in Switzerland. Finally, this study was partly supported by the Swiss National Science Foundation (SNF, grant 31ED30114213) through funds to M. O. Gessner for his participation in BioCycle, a collaborative research project of the European Science Foundation's (ESF) EURODIVERSITY program. BioCycle has been endorsed by DIVERSITAS as contributing to its biodiversity research priorities.

\section{Literature Cited}

Arsuffi, T. L., and K. Suberkropp. 1989. Selective feeding by shredders on leaf-colonizing stream fungi: comparison of macroinvertebrate taxa. Oecologia 79:30-37.

Bretherton, W. D., J. S. Kominoski, D. G. Fischer, and C. J. Leroy. 2011. Salmon carcasses alter leaf litter species diversity effects on in-stream decomposition. Canadian Journal of Fisheries and Aquatic Sciences 68:1495-1506.

Cardinale, B. J., et al. 2012. Biodiversity loss and its impact on humanity. Nature 486:59-67.

Cardinale, B. J., K. L. Matulich, D. U. Hooper, J. E. Byrnes, E. Duffy, L. Gamfeldt, P. Balvanera, M. I. O'Connor, and A. Gonzalez. 2011. The functional role of producer diversity in ecosystems. American Journal of Botany 98:572-592.

Ebina, J., T. Tsutsui, and T. Shirai. 1983. Simultaneous determination of total nitrogen and total phosphorus in water using peroxodisulfate oxidation. Water Research 17: $1721-1726$.

Enriquez, S., C. Duarte, and K. Sand-Jensen. 1993. Patterns in decomposition rates among photosynthetic organisms: the importance of detritus C:N:P content. Oecologia 94:457-471.

Ferreira, V., V. Gulis, and M. A. S. Graça. 2006. Whole-stream nitrate addition affects litter decomposition and associated fungi but not invertebrates. Oecologia 149:718-729.

Freschet, G. T., R. Aerts, and J. H. C. Cornelissen. 2011. A plant economics spectrum of litter decomposability. Functional Ecology 26:56-65.

Gamfeldt, L., H. Hillebrand, and P. R. Jonsson. 2008. Multiple functions increase the importance of biodiversity for overall ecosystem functioning. Ecology 89:1223-1231.

Gamfeldt, L., et al. 2013. Higher levels of multiple ecosystem services are found in forests with more tree species. Nature Communications 4:1340.

Gartner, T. B., and Z. G. Cardon. 2004. Decomposition dynamics in mixed-species leaf litter. Oikos 104:230-246. 
Gessner, M. O. 2005a. Proximate lignin and cellulose. Pages 115-120 in M. A. S. Graça, F. Bärlocher, and M. O. Gessner, editors. Methods to study litter decomposition: a practical guide. Springer-Verlag, Dordrecht, The Netherlands.

Gessner, M. O. 2005b. Ergosterol as a measure of fungal biomass. Pages 189-196 in M. A. S. Graça, F. Bärlocher, and M. O. Gessner, editors. Methods to study litter decomposition: a practical guide. Springer-Verlag, Dordrecht, The Netherlands.

Gessner, M. O. 2010. Functional leaf traits and biodiversity effects on litter decomposition in a stream: reply. Ecology 91: 1869-1871.

Gessner, M. O., and E. Chauvet. 1993. Ergosterol-to-biomass conversion factors for aquatic hyphomycetes. Applied and Environmental Microbiology 59:502-507.

Gessner, M. O., and E. Chauvet. 1994. Importance of stream microfungi in controlling breakdown rates of leaf-litter. Ecology 75:1807-1817.

Gessner, M. O., and A. L. Schmitt. 1996. Use of solid-phase extraction to determine ergosterol concentrations in plant tissue colonized by fungi. Applied and Environmental Microbiology 62:415-419.

Gessner, M. O., C. M. Swan, C. K. Dang, B. G. McKie, R. D. Bardgett, D. H. Wall, and S. Hättenschwiler. 2010. Diversity meets decomposition. Trends in Ecology and Evolution 25: 372-380.

Goslee, S. C., and D. L. Urban. 2007. The ecodist package for dissimilarity-based analysis of ecological data. Journal of Statistical Software 22:1-19.

Graça, M. A. S. 2001. The role of invertebrates on leaf litter decomposition in streams-a review. International Review of Hydrobiology 86:383-393.

Gulis, V., K. A. Kuehn, and K. Suberkropp. 2009. Fungi. Pages 233-243 in G. E. Likens, editor. Encyclopedia of inland waters. Elsevier, Dordrecht, The Netherlands.

Handa, I. T., et al. 2014. Consequences of biodiversity loss for litter decomposition across biomes. Nature 509:218-221.

Hättenschwiler, S., A. V. Tiunov, and S. Scheu. 2005. Biodiversity and litter decomposition in terrestrial ecosystems. Annual Review of Ecology, Evolution, and Systematics $36: 191-218$

Hector, A., and R. Bagchi. 2007. Biodiversity and ecosystem multifunctionality. Nature 448:188-190.

Heemsbergen, D. A., M. P. Berg, M. Loreau, J. R. van Hal, J. H. Faber, and H. A. Verhoef. 2004. Biodiversity effects on soil processes explained by interspecific functional dissimilarity. Science 306:1019-1020.

Hieber, M., and M. O. Gessner. 2002. Contribution of stream detrivores, fungi, and bacteria to leaf breakdown based on biomass estimates. Ecology 83:1026-1038.

Hladyz, S., M. O. Gessner, P. S. Giller, J. Pozo, and G. Woodward. 2009. Resource quality and stoichiometric constraints on stream ecosystem functioning. Freshwater Biology 54:957-970.

Kominoski, J. S., C. M. Pringle, B. A. Ball, M. A. Bradford, D. C. Coleman, D. B. Hall, and M. D. Hunter. 2007. Nonadditive effects of leaf litter species diversity on breakdown dynamics in a detritus-based stream. Ecology 88:1167-1176.

Krauss, G.-J., M. Solé, G. Krauss, D. Schlosser, D. Wesenberg, and F. Bärlocher. 2011. Fungi in freshwaters: ecology, physiology and biochemical potential. FEMS Microbiology Reviews 35:620-651.

Lecerf, A., and J. Kominoski. 2010. Functional leaf traits and biodiversity effects on litter decomposition in a stream: comment. Ecology 91:1867-1869.

Lecerf, A., G. Marie, J. S. Kominoski, C. J. Leroy, C. Bernadet, and C. M. Swan. 2011. Incubation time, functional litter diversity, and habitat characteristics predict litter-mixing effects on decomposition. Ecology 92:160-169.

Lecerf, A., and J. S. Richardson. 2009. Biodiversity-ecosystem function research: insights gained from streams. River Research and Applications 26:45-54.

Leroy, C. J., and J. C. Marks. 2006. Litter quality, stream characteristics and litter diversity influence decomposition rates and macroinvertebrates. Freshwater Biology 51:605617

Leroy, C. J., T. G. Whitham, S. C. Wooley, and J. C. Marks. 2007. Within-species variation in foliar chemistry influences leaf-litter decomposition in a Utah river. Journal of the North American Benthological Society 26:426-438.

Lummer, D., S. Scheu, and O. Butenschoen. 2012. Connecting litter quality, microbial community and nitrogen transfer mechanisms in decomposing litter mixtures. Oikos 121:16491655.

Maechler, M., P. Rousseeuw, A. Struyf, M. Hubert, and K. Hornik. 2011. cluster: Cluster analysis basics and extensions. $\mathrm{R}$ package version 1.14.1. R Foundation for Statistical Computing, Vienna, Austria.

Manzoni, S., R. B. Jackson, J. A. Trofymow, and A. Porporato. 2008. The global stoichiometry of litter nitrogen mineralization. Science 321:684-686.

McKie, B. G., M. Schindler, M. O. Gessner, and B. Malmqvist. 2009. Placing biodiversity and ecosystem functioning in context: environmental perturbations and the effects of species richness in a stream field experiment. Oecologia 160: 757-770.

Melillo, J. M., J. D. Aber, and J. F. Muratore. 1982. Nitrogen and lignin control of hardwood leaf litter decomposition dynamics. Ecology 63:621-626.

Mouillot, D., N. A. J. Graham, S. Villéger, N. W. H. Mason, and D. R. Bellwood. 2013. A functional approach reveals community responses to disturbances. Trends in Ecology and Evolution 28:167-177.

Oksanen, J., F. G. Blanchet, R. Kindt, P. Legendre, P. R. Minchin, R. B. O'Hara, G. L. Simpson, P. Solymos, M. H. H. Stevens, and H. Wagner. 2011. vegan: Community ecology. R package version 2.0-2. R Foundation for Statistical Computing, Vienna, Austria.

Parton, W., et al. 2007. Global-scale similarities in nitrogen release patterns during long-term decomposition. Science 315:361-364

Perkins, D. M., R. A. Bailey, M. Dossena, L. Gamfeldt, J. Reiss, M. Trimmer, and G. Woodward. 2014. Higher biodiversity is required to sustain multiple ecosystem processes across temperature regimes. Global Change Biology. http://dx.doi.org/10.1111/gcb.12688

Petchey, O. L., and K. J. Gaston. 2002. Functional diversity (FD), species richness and community composition. Ecology Letters 5:402-411.

Petchey, O. L., and K. J. Gaston. 2007. Dendrograms and measuring functional diversity. Oikos 116:1422-1426.

Pinheiro, J., D. Bates, S. DebRoy, D. Sarkar, and R Core Team. 2012. nlme: linear and nonlinear mixed effects models. $\mathrm{R}$ package version 31-104. R Foundation for Statistical Computing, Vienna, Austria.

Podani, J., and D. Schmera. 2006. On dendrogram-based measures of functional diversity. Oikos 115:179-185.

R Development Core Team. 2012. R: A language and environment for statistical computing. R Foundation for Statistical Computing, Vienna, Austria.

Reich, P. B. P., D. D. Tilman, F. F. Isbell, K. K. Mueller, S. E. S. Hobbie, D. F. B. D. Flynn, and N. N. Eisenhauer. 2012. Impacts of biodiversity loss escalate through time as redundancy fades. Science 336:589-592. 
Richardson, J. S. 1992. Food, microhabitat, or both? Macroinvertebrate use of leaf accumulations in a montane stream. Freshwater Biology 27:169-176.

Ritz, K. 2006. Fungal roles in transport processes in soils. Pages 51-73 in M. G. Gadd, editor. Fungi in biogeochemical cycles. Cambridge University Press, Cambridge, UK.

Rosemond, A. D., C. M. Swan, J. S. Kominoski, and S. E. Dye. 2010. Non-additive effects of litter mixing are suppressed in a nutrient-enriched stream. Oikos 119:326-336.

Schimel, J. P., and S. Hättenschwiler. 2007. Nitrogen transfer between decomposing leaves of different $\mathrm{N}$ status. Soil Biology and Biochemistry 39:1428-1436.

Schindler, M. H., and M. O. Gessner. 2009. Functional leaf traits and biodiversity effects on litter decomposition in a stream. Ecology 90:1641-1649.

Schleuter, D., M. Daufresne, F. Massol, and C. Argillier. 2010. A user's guide to functional diversity indices. Ecological Monographs 80:469-484.

Srivastava, D. S., B. J. Cardinale, A. L. Downing, J. E. Duffy, C. Jouseau, M. Sankaran, and J. P. Wright. 2009. Diversity has stronger top-down than bottom-up effects on decomposition. Ecology 90:1073-1083.

Suberkropp, K. 1991. Relationships between growth and sporulation of aquatic hyphomycetes on decomposing leaf litter. Mycological Research 95:843-850.

Suberkropp, K., V. Gulis, A. D. Rosemond, and J. P. Benstead. 2010. Ecosystem and physiological scales of microbial responses to nutrients in a detritus-based stream: results of a 5-year continuous enrichment. Limnology and Oceanography 55:149-160.
Suding, K. N., and L. J. Goldstein. 2008. Testing the Holy Grail framework: using functional traits to predict ecosystem change. New Phytologist 180:559-562.

Sutherland, W. J., et al. 2013. A horizon scan of global conservation issues for 2013. Trends in Ecology and Evolution 28:16-22.

Talbot, J. M. J., and K. K. K. Treseder. 2012. Interactions among lignin, cellulose, and nitrogen drive litter chemistrydecay relationships. Ecology 93:345-354.

Vörösmarty, C. J., et al. 2010. Global threats to human water security and river biodiversity. Nature 467:555-561.

Vos, V. C. A., J. Ruijven, M. P. Berg, E. T. H. M. Peeters, and F. Berendse. 2013. Leaf litter quality drives litter mixing effects through complementary resource use among detritivores. Oecologia 173:269-280.

Walker, B., A. Kinzig, and J. Langridge. 1999. Plant attribute diversity, resilience, and ecosystem function: the nature and significance of dominant and minor species. Ecosystems 2: 95-113.

Webster, J. R., and E. F. Benfield. 1986. Vascular plant breakdown in freshwater ecosystems. Annual Review of Ecology and Systematics 17:567-594.

Webster, J. R., J. D. Newbold, S. A. Thomas, H. M. Valett, and P. J. Mulholland. 2009. Nutrient uptake and mineralization during leaf decay in streams: a model simulation. International Review of Hydrobiology 94:372-390.

Wieder, W. R., C. C. Cleveland, and A. R. Townsend. 2009. Controls over leaf litter decomposition in wet tropical forests. Ecology 90:3333-3341.

Woodward, G., et al. 2012. Continental-scale effects of nutrient pollution on stream ecosystem functioning. Science 336: $1438-1440$.

\section{Supplemental Material}

\section{Ecological Archives}

Appendices A-C are available online: http://dx.doi.org/10.1890/14-1151.1.sm 